\title{
Impact of air pollution on physician office visits for common childhood conditions in Ontario, Canada
}

\author{
Laura Feldman ${ }^{1,2^{*}}$, Chenwei Gao ${ }^{1,3}$, Jingqin Zhu ${ }^{1,3}$, Jacqueline Simatovic ${ }^{1}$, Teresa To ${ }^{1,2,3}$ \\ From Canadian Society of Allergy and Clinical Immunology Annual Scientific Meeting 2014 \\ Ottawa, ON, Canada. 23-26 October 2014
}

\section{Background}

Children are particularly sensitive to air pollutants, due to factors such as ongoing lung development and choice of activities [1]. We evaluated the impact of fine particulate matter $\left(\mathrm{PM}_{2.5}\right)$ on physician office visits for common conditions in children in Ontario, Canada.

\section{Methods}

$\mathrm{PM}_{2.5}$ and temperature measurements were obtained from satellite data for all of Ontario [2]. Physician office visits were stratified into two groups based on the literature: air pollution-sensitive (acute respiratory infections, allergic rhinitis, asthma, bronchiolitis, diabetes, otitis media) and air pollution-insensitive (gastroenteritis, injuries). Claims data were obtained for every month in 2010 from health administrative databases for children 0-14 years of age. Age- and sex-standardized morbidity ratios (SMRs) were calculated by region in Ontario. Spatial Poisson regression models were used to analyze the relationship between $\mathrm{PM}_{2.5}$ and physician office visits, with temperature as a covariate.

\section{Results}

Crude rates of physician office visits are presented in Table 1. As expected, fine particulate was significantly associated with monthly rates of physician office visits for air pollution-sensitive conditions, and not for insensitive conditions. Fitted SMRs for air pollution-sensitive conditions are presented in Figure 1. SMRs for sensitive and insensitive conditions were strongly positively correlated $(r=0.53)$, and data were spatially autocorrelated. This suggests an underlying spatial process that influences physician office visit rates for common childhood conditions, both for air pollution-sensitive and -insensitive conditions.

\section{Conclusions}

In this analysis $\mathrm{PM}_{2.5}$, was significantly associated with physician office visits for air pollution-sensitive conditions. Areas with high PM2.5 levels and SMRs higher than 1 were identified; children with air pollution-sensitive conditions in these areas may benefit from targeted air

Table 1 Crude rates of air pollution-sensitive and air pollution-insensitive conditions in Ontario for each month in 2010

\begin{tabular}{lcccccccccccc}
\hline & \multicolumn{1}{c}{} & \multicolumn{1}{c}{ Crude rates of physician office visits $^{\mathrm{a}}$} \\
\hline & Jan & Feb & Mar & Apr & May & June & July & Aug & Sept & Oct & Nov & Dec \\
\hline Air pollution-sensitive & 8.05 & 8.84 & 8.94 & 7.80 & 7.21 & 6.55 & 5.15 & 4.73 & 6.57 & 7.52 & 9.27 & 10.89 \\
\hline Air pollution-insensitive & 1.48 & 1.52 & 1.61 & 1.55 & 1.63 & 1.63 & 1.34 & 1.29 & 1.34 & 1.38 & 1.54 & 1.22 \\
\hline
\end{tabular}

${ }^{\mathrm{a}}$ Number of claims per 100 population aged 0-14 years.

\footnotetext{
* Correspondence: I.feldman@mail.utoronto.ca

${ }^{1}$ Child Health Evaluative Sciences, The Hospital for Sick Children, Toronto,

Ontario, M5G 1X8, Canada

Full list of author information is available at the end of the article
} 


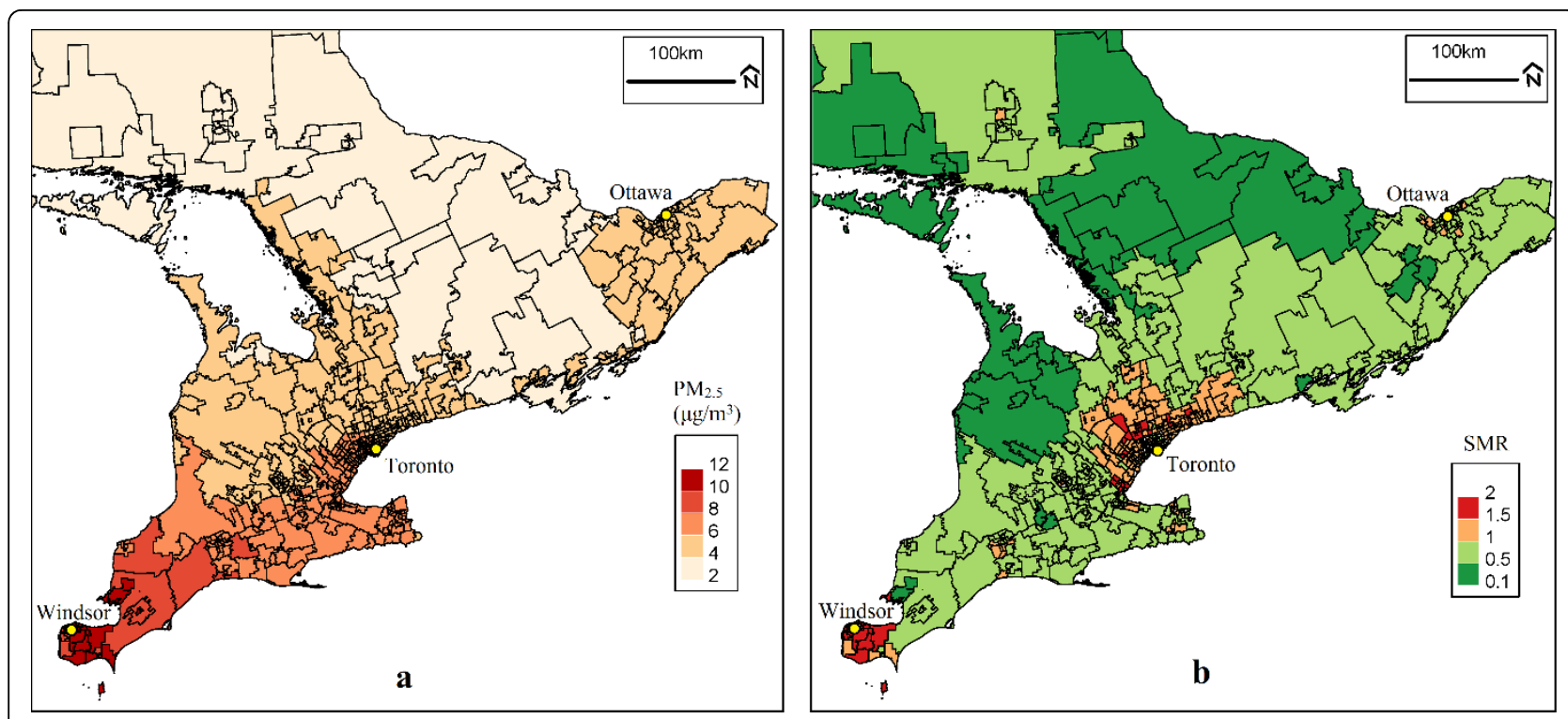

Figure 1 Distribution of (a) fine particulate matter $\left(\mathrm{PM}_{2.5}\right.$, in $\mu \mathrm{g} / \mathrm{m}^{3}$ ) and (b) fitted sex-standardized morbidity ratios (SMRs) from spatial Poisson regression for physician office visits for air pollution-sensitive conditions; all by Forward Sortation Area (FSA) in Southern Ontario in July 2010

pollution reduction interventions. Additionally, future analysis should evaluate the role of household income and access to care in influencing the spatial pattern of primary health care utilization for common childhood conditions across Ontario.

\section{Authors' details}

${ }^{1}$ Child Health Evaluative Sciences, The Hospital for Sick Children, Toronto, Ontario, M5G 1X8, Canada. 'University of Toronto, Toronto, Ontario, M5S 1A1, Canada. ${ }^{3}$ Institute for Clinical Evaluative Sciences, North York, Ontario, M5T 3M6, Canada.

Published: 18 December 2014

\section{References}

1. WHO-Europe: Effects of Air Pollution on Children's Health and Development. A Review of the Evidence. Special Programme on Health and Environment Bonn: World Health Organization, European Centre for Environment and Health; 2005.

2. Battelle Memorial Institute, Center for International Earth Science Information Network CIESIN - Columbia University: Global Annual Average PM2.5 Grids from MODIS and MISR Aerosol Optical Depth (AOD).

Palisades, NY: NASA Socioeconomic Data and Applications Center (SEDAC); 2013.

doi:10.1186/1710-1492-10-S2-A54

Cite this article as: Feldman et al.: Impact of air pollution on physician office visits for common childhood conditions in Ontario, Canada. Allergy, Asthma and Clinical Immunology 2014 10(Suppl 2):A54.

\section{Submit your next manuscript to BioMed Central and take full advantage of:}

- Convenient online submission

- Thorough peer review

- No space constraints or color figure charges

- Immediate publication on acceptance

- Inclusion in PubMed, CAS, Scopus and Google Scholar

- Research which is freely available for redistribution 